\title{
O CARÁTER AMBIVALENTE DA FICÇÃO DE MIA COUTO EM CADA HOMEM É UMA RAÇA
}

\author{
Alcione Manzoni Bidinoto*
}

O presente texto constrói-se como uma tentativa de abordagem dos contos de Cada homem é uma raça ${ }^{1}$, de Mia Couto, escritor nascido na cidade da Beira, Moçambique, em 1955. Cada homem é uma raça (1990), seu segundo livro de narrativas curtas, é constituído por onze contos, cuja ação desenvolve-se em diferentes momentos históricos, desde os tempos coloniais até os anos posteriores à independência do país.

Um aspecto da prosa de Mia Couto que a torna interessante, principalmente entre os leitores de Literatura Brasileira, é o intenso processo de invenção lexical nela operado: a norma padrão da língua é transgredida, criam-se novas palavras, altera-se a sintaxe para exprimir novos sentidos; a Língua Portuguesa é trabalhada para se adequar a uma realidade cultural específica. A criação verbal, associada ao uso de provérbios, produz na escrita de Mia Couto um efeito de oralidade que busca resgatar histórias, mitos e crenças da tradição do povo moçambicano. Devido a esse trabalho com a linguagem, têm sido apontadas várias semelhanças entre a obra do escritor moçambicano e a do brasileiro Guimarães Rosa. Existe, inclusive, um bom número de estudos desenvolvidos a partir da escrita dos dois.

Um outro aspecto da ficção de Mia Couto que chama a atenção logo numa primeira leitura é o fato de suas narrativas apresentarem, simultaneamente, uma feição realista - perceptível na narração de eventos históricos relacionados com as guerras coloniais e com a guerra civil, bem como com a situação decorrente dessas lutas - e uma outra feição (a qual não será nomeada por enquanto) em que aparecem acontecimentos insólitos, além das crenças e mitos pertencentes ao "imaginário africano".

O objetivo deste trabalho é propor um caminho de análise dos contos a partir do estranhamento provocado pelo que se poderia chamar de "caráter ambivalente" dessas narrativas. Com base nas considerações do teórico russo E. M. Mielietinski sobre a relação entre história e mito na literatura do século $X X$, tenta-se investigar como se apresentam nas narrativas de Mia Couto o plano histórico e o plano mítico. Procura-se fazer, ainda, uma leitura do elemento 
simbólico, que inclui o mito como uma de suas formas.

\section{Mito, história e identidade cultural}

De acordo com Mielietinski, a utilização do mito, seja como procedimento artístico ou como visão do mundo que fundamenta esse procedimento, é um fenômeno significativo da literatura do século $X X^{2}$ A partir dos anos 50-60, a "poética da mitologização" começa a ser observada nas literaturas latino-americanas e afroasiáticas. No caso dessas literaturas podem coexistir "as tradições folclóricas arcaicas e a consciência folclórico-mitológica [...] com o intelectualismo modernista de tipo puramente europeu"3. Essa situação histórica e cultural possibilita que elementos de historicismo e mitologismo estejam presentes ao mesmo tempo nos romances. Mielietinski observa ainda que, embora o "mito" e a "história" apresentem-se sempre como opostos, por outro lado, não podem ser separados na literatura mitologizante do século $X X^{4}$. Serão levados em conta os pressupostos básicos de Mielietinski, que afirmam a importância do mito para a literatura do século $X X$ e a coexistência dos aspectos mitológicos e históricos nas narrativas das literaturas de "terceiro mundo", para se buscar a abordagem dos contos de Mia Couto.

Entende-se mito neste trabalho, de acordo com a concepção do historiador das religiões Mircea Eliade, como "história verdadeira", narrativa "extremamente preciosa por seu caráter sagrado, exemplar e significativo" ${ }^{15}$. É interessante notar que os textos de Mia Couto são escritos a partir de um lugar cultural em que o mito é muitas vezes vivo no interior das comunidades. Deve-se, então, tratar de um outro aspecto existente na sua ficção que diz respeito a esse assunto: as representações das culturas africana e européia (e asiática em menor escala) e os pontos de cruzamento e interferência entre essas culturas. Elas não são vistas, entretanto, como determinantes de identidades culturais, já que estas são compreendidas, nesta pesquisa, "não como essencializações [...], mas como conjuntos contrapontuais, pois a questão é que nenhuma identidade pode existir por si só, sem um leque de opostos, oposições e negativas" ${ }^{\prime 6}$. A identidade seria constituída, então, no confronto dos elementos das diversas culturas envolvidas no processo. De acordo com o crítico pós-colonial Edward Said, "a experiência cultural, ou na verdade toda forma cultural, é radicalmente, quintessencialmente híbrida"”. 
Portanto, quando se afirma que a sociedade africana está relacionada estreitamente ao pensamento mítico e a européia é racional e científica, deve-se levar em conta como se apresentam os matizes dessas duas visões do mundo. No caso das narrativas de Mia Couto, estas parecem conseguir, se não conciliar, ao menos justapor as duas visões, as quais se apresentam fundidas numa linguagem híbrida. Essa forma de nomear as coisas se assemelha ao modo realista maravilhoso de narrar.

\section{0 modo realista: a representação da história}

As narrativas aqui estudadas podem ser consideradas como apresentando alto grau de referência com relação à realidade empírica do país onde são produzidas. É necessário esclarecer que Moçambique foi colônia de Portugal desde o final do século XV. A sua Libertação, assim como a das demais colônias portuguesas na África - Angola, Guiné-Bissau e Cabo Verde - ocorreu somente na metade da década de 1970. A Revolução dos Cravos, com a queda de Salazar e a instauração do regime socialista em Portugal, em abril de 1974, acelerou o processo que vinha se desenvolvendo desde, pelo menos, o começo da década anterior nos territórios africanos. Moçambique foi reconhecido como nação independente em 25 de junho de 1975. Antes, porém, transcorreram mais de dez anos de luta anticolonial, levada a cabo por guerrilheiros do movimento revolucionário de fundo marxista da FRELIMO (Frente de Libertação de Moçambique). A partir dessa data, o país mergulhou numa devastadora guerra civil que se estendeu por vários anos, até 1992.

Nos contos de Cada homem é uma raça, podem ser identificadas, nos episódios ou situações das narrativas, as marcas de referência à realidade empírica de Moçambique. O conto $O$ Apocalipse privado do tio Geguê, terceiro do livro, narra a história de Geguê e seu sobrinho. Tudo começa quando Geguê encontra uma bota. Dizem-lhe que deve livrar-se dela, e ele a joga no pântano. Naquela noite, Zabelani, também sobrinha de Geguê, chega à casa em que moram os dois. O rapaz, narrador do conto, envolve-se com Zabelani. Então Geguê leva a moça de casa e a esconde, dizendo ao jovem que somente Ihe será permitido recuperá-la se ele estiver disposto a executar suas ordens. A partir daí, o sobrinho, essa personagem sem nome, passa a protagonizar maldades, roubos e outros delitos, às escondidas, à noite. Durante o dia, ele e Geguê 
desempenham a função de vigilantes da guarda revolucionária, na qual também provocam confusão, utilizando-se de métodos violentos. Um dia, passando pelo pântano, o jovem encontra a bota abandonada e resolve procurar Zabelani. Quando descobre o paradeiro de sua prima, ela já fora levada pelo tio. Então ele volta a casa e, com a arma que Geguê Ihe dera, dispara contra seu tio, a pedido deste. Depois foge, sem saber o destino do projétil.

Num determinado momento da narrativa, diz-se a propósito da bota encontrada por Geguê: "A botifarra estava garantida pela história: tinha percorrido os gloriosos tempos da luta pela independência" (p. 30). Existe a localização da narrativa em um tempo posterior ao 25 de junho de 1975. No entanto, se os tempos da luta foram "gloriosos", os do presente não o são. Por obra de Geguê e seu sobrinho - cuja posse da "braçadeira vermelha" de vigilante assegurava a autoridade e os desmandos - "nascera" uma guerra no povoado:

Casa, carro, propriedades: tudo se tinha tornado demasiado mortal. Tão cedo havia, tão cedo ardia. Entre os mais velhos já se espalhava a saudade do antigamente.

- Mais valia a pena...

(...) Alguns se amargavam, fazendo conta aos sacrifícios:

- Foi para isso que lutamos? (p. 41)

A situação do povoado desse conto representa, de maneira alegórica, o estado do país nos anos subseqüentes à libertação do domínio português, em que se instalou uma grande desordem devido à guerra civil. Essa guerra, representada na narrativa, é o conflito iniciado pouco tempo depois da descolonização, e que envolveu principalmente a guerrilha da FRELIMO e a RENAMO (Resistência Nacional de Moçambique) - grupo formado por dissidentes do regime, apoiado por portugueses que haviam sido destituídos do poder, rodesianos e sul-africanos. Conforme o teórico indiano Aijaz Ahmad, em alguns países, como os do sul da África, que venceram suas guerras de libertação na metade da década de 1970, foi possível ver com clareza a dinâmica de uma luta anticolonial transformando-se numa luta socialista ${ }^{8}$. Entretanto, afirma Ahmad, os movimentos revolucionários de independência dos países africanos e asiáticos do século XX que tentaram substituir as sociedades coloniais por sociedades socialistas não tiveram êxito. 
Ocorreu, ao contrário, o fortalecimento da burguesia nacional, com conseqüências funestas para esses países ${ }^{9}$.

No fragmento citado é notável o sentimento de desilusão diante de uma realidade que não corresponde àquela sonhada $e$ buscada em anos de lutas motivadas pelos ideais socialistas, uma realidade perante a qual o "antigamente" dos tempos coloniais se afigura como algo menos desditoso e, até mesmo, mais desejável.

Nesse tempo em que o português ainda era o senhor e detinha o poder, sem oponentes, passa-se a história de $O$ embondeiro que sonhava pássaros, quarto conto da obra. Nessa narrativa, a calma e a normalidade de um bairro de brancos passam a ser ameaçadas pelo canto e pelas cores de pássaros trazidos por um vendedor negro. O nativo e sua exótica mercadoria seduzem as crianças do lugar, principalmente um menino de nome Tiago, cuja habilidade maior é a de "perseguir fantasias". Incomodados com a subversiva presença do passarinheiro e com a indisciplina dos filhos, os colonos proíbem 0 acesso destes à rua. Então acontecimentos estranhos começam a ocorrer, como a abertura de portas e janelas, a modificação do lugar dos móveis e a troca de gavetas, sem intervenção humana. Ao vendedor é imputada a culpa dessas ocorrências, e decide-se prendê-lo. Tiago, depois de ouvir a conversa dos adultos, corre até o embondeiro, árvore que serve de moradia ao passarinheiro, para avisá-lo. Mesmo assim, ele se deixa agredir e levar até a prisão do povoado. No final, tendo o vendedor se evadido da prisão de maneira misteriosa, saem os colonos à sua procura. Ao ouvirem o som da gaita de boca do negro saindo da árvore que lhe serve de morada, eles colocam fogo no tronco. Mas quem está no interior da árvore é o menino Tiago, à espera de se amigo.

No conto é possível notar, nas palavras e atitudes dos colonos, a ambigüidade que, segundo o crítico indo-britânico Bhabha $^{10}$, é própria do discurso colonial e constitui o estereótipo: o duplo movimento de atração e repulsa pelo outro, pelo diferente. Ao mesmo tempo, a figura do vendedor provoca fascínio e medo pelo que tem de escondido, de misterioso. A causa do confronto está também nas diferentes sensibilidades, decorrentes de visões do mundo e estruturas de pensamento distintas.

\section{O modo mítico}

\subsection{A transfiguração do real}


Os elementos relacionados com o mito ou com uma visão mítica do mundo também são muito freqüentes nas narrativas. Há a narração de acontecimentos insólitos, nos quais ocorre a subversão das leis naturais do modo como elas são concebidas pelo pensamento racional. No conto O pescador cego, Maneca Mazembe arranca seus próprios olhos para utilizá-los como isca, numa ocasião em que fora acometido de terrível fome, estando perdido em pleno mar. Graças aos peixes fisgados, ele se mantém vivo até chegar de volta à praia de sua aldeia. Esses já são acontecimentos cujo tom de estranhamento e desconformidade com as leis da realidade se fazem notar. Quando Salima, sua mulher, manifesta a vontade de sair com o barco para pescar, Maneca pró́be-a, arrasta o barco para longe da água e passa a viver dentro dele. Um dia, malgrado as advertências de Salima quanto à desgraça que isto provocaria, o pescador coloca fogo no barco. A mulher e os filhos o abandonam. Um tempo depois, ocorre algo inusitado:

Certa noite [...], se confirmou o presságio de Salima: aquele fogo voara demasiado alto, incomodando os espíritos. Porque, do topo dos coqueiros, o vento se deu de uivar. Mazembe se afligiu, o chão mesmo se arrepiou. Súbito, o céu se rasgou e grossas pedras de gelo tombaram em toda a praia. $\mathrm{O}$ pescador corria no vazio, à procura de abrigo. $\mathrm{O}$ granizo, implacável, Ihe castigava. Maneca desconhecia explicação. Nunca ele se cruzara com tais fenômenos. A terra subiu para o céu, pensou. Virado do avesso, o mundo deixava tombar seus materiais. (p. 103)

É inconcebível para uma racionalidade dita científica aceitar que tais eventos possam realmente ter lugar: como pode uma tempestade tão grande e avassaladora ser desencadeada pela fumaça do incêndio de um barco? É impossível, porém, deixar de notar a relação de causa e efeito estabelecida entre a queima da embarcação e os fenômenos meteorológicos. Não há dúvida de que se trata de uma punição por um ato reprovado pelos espíritos. Não seria esse fato um exemplo de revelação da "causalidade onipresente" do realismo maravilhoso - conforme teorizado por Chiampi - que provoca um efeito de encantamento do leitor "pela percepção da contigüidade entre as esferas do real e do irreal"11? 
Alguns dos críticos que se dedicaram ao estudo da obra de Mia Couto têm preferido analisá-la sob a ótica do fantástico, de acordo com a concepção de Torodov. Esse tipo de abordagem, no entanto, dificilmente se sustenta. Numa consideração preliminar e, por isso, limitada, para invalidar esse ponto de vista bastaria afirmar que nos textos de Mia Couto não ocorre a hesitação do leitor entre uma explicação natural e uma explicação sobrenatural para um acontecimento que não pode ser entendido racionalmente condição principal para a existência do fantástico, segundo Todorov $^{12}$. Não existe nem mesmo um questionamento sobre a realidade dos fenômenos por parte das personagens, embora possa haver uma indagação dos motivos de tais ocorrências. No conto $O$ Apocalipse privado do tio Geguê, após retomar a bota que seu sobrinho não quisera calçar, Geguê resolve livrar-se dela:

Pegou na bota e atirou para longe. O estranho então sucedeu: lançada no ar a bota ganhou competência volátil. A coisa voejava em velozes rodopios. O tio Geguê desafiara os espíritos da guerra? (p. 31)

Na pergunta do narrador, lê-se a afirmação da possibilidade da existência de tais eventos: num mundo em que se acredita na intervenção dos espíritos dos antepassados, como é o mundo africano, é possível que coisas "estranhas" aconteçam. De maneira semelhante à caracterização do continente americano, por Carpentier, como o território do "real maravilhoso americano"13, poder-se-ia caracterizar a África ${ }^{14}$ como um espaço cultural em que determinados eventos, "maravilhosos" para a concepção do europeu, são "reais" para o africano.

No conto $O$ embondeiro que sonhava pássaros, o uso da paralepse ou excesso de informação - que consiste nesse caso "numa incursão na consciência de uma personagem no decorrer de uma narrativa geralmente conduzida em focalização externa"15 torna de certa maneira a relação com o insólito menos aceitável em determinados momentos. Isso ocorre justamente quando a narração é feita a partir da consciência dos portugueses:

Afinal, os colonos ainda que hesitaram: aquele negro trazia aves de belezas jamais vistas. Ninguém podia resistir às suas cores, seus chilreios. Nem aquilo não parecia coisa deste verídico mundo. (p. 65, grifo nosso) 
O fator cultural deve ser novamente considerado: elementos que fazem parte da realidade de alguns povos africanos são percebidos como irreais pelos europeus. Entretanto se enunciados como este - "Nem aquilo não parecia coisa deste verídico mundo" podem instaurar uma dúvida provocando a hesitação a respeito da naturalidade ou sobrenaturalidade dos fatos, essa indefinição não se mantém por muito tempo. Depois de ir até o embondeiro para avisar o vendedor de pássaros sobre a decisão dos colonos, Tiago fica um instante sozinho junto da árvore:

A criança se hesitava, passo atrás, passo adiante. Então, foi então: as flores do embondeiro tombaram, pareciam astros de feltro. No chão, suas brancas pétalas, uma a uma se avermelharam. (p. 69)

Não existe um questionamento, seja por parte do narrador, seja por parte da personagem a respeito do acontecimento. Não chega a ser colocada nenhuma outra hipótese que permita duvidar do acontecido. O insólito, além disso, não causa desconcerto na personagem nem motiva a modalização do discurso do narrador na sua apresentação. Esse procedimento, via de regra reiterado nas narrativas estudadas, é mais um motivo para aproximar a ficção do escritor moçambicano da categoria do realismo maravilhoso ${ }^{16}$.

Um outro elemento referido por Chiampi como constitutivo do tipo de ficção produzido pelos autores latino-americanos por ela estudados, o qual também se encontra em Cada homem é uma raça, é o da enunciação problematizada. Ocorre um desmascaramento do narrador, consumado pela "problematização que a voz opera sobre o ato de contar"17. Isso pode ser percebido, por exemplo, nos dois primeiros parágrafos de $O$ Apocalipse privado do tio Geguê:

História de um homem é sempre mal contada. Porque a pessoa é, em todo o tempo, ainda nascente. Ninguém segue uma única vida, todos se multiplicam em diversos e transmutáveis homens.

Agora, quando desembrulho minhas lembranças eu aprendo meus muitos idiomas. Nem assim me entendo. Porque enquanto me descubro, eu mesmo me anoiteço, fosse haver coisas só visíveis em plena cegueira. (p. 29) 
A capacidade de contar a própria história é colocada em dúvida pela voz crítica do narrador, primeiro num nível mais geral, depois numa condição mais particular. Essa dificuldade relaciona-se tanto com o problema de tornar compreensível para os outros o relato de uma existência, quanto com o fato de que essa compreensão passa pela recuperação e seleção das lembranças. Em O pescador cego, existe algo semelhante: "Há dessas estórias que, quanto mais se contam, menos se conhece. Muitas vozes, afinal, só produzem silêncio" (p. 97). Nesses enunciados, os quais se disseminam em quase todos os contos da obra, dá-se o desvelamento do narrador. Ele deixa de estar oculto e se mostra como responsável pelo ato da narração. Com isso, assume os riscos de sua função, abandonado a certeza e a objetividade da onisciência.

\subsection{A transformação pela palavra}

Pensando nesse locus cultural diferenciado a partir de onde se está narrando, pode-se considerar um segundo modo pelo qual o inusitado entra na narrativa, dessa vez, não através da transfiguração do real, mas pela maneira de nomear as coisas. Leiase um fragmento da descrição do espaço de Os mastros do Paralém, último conto do livro:

A chuva é carcereira, fechando a gente. Prisioneiros da chuva estavam Constante Bene e seus todos filhos, encerrados na cabana. Nunca tamanha água fora vista: a paisagem pingava há dezassete dias. Mal ensinada a nadar, a água magoava a terra. Sobre as telhas de zinco, se acotovelavam grossas gotas, grávidas de céu. Na encosta do monte, só as árvores teimavam, sem nunca se interromperem. (p. 167)

Note-se que se produz, nessa caracterização da paisagem, um efeito de estranhamento, se não de encantamento. Esse efeito provavelmente se deve à utilização de um processo de personificação. Mas a seleção lexical operada não visa apenas à construção de uma simples figura, e sim à criação de um novo modo de apreensão da realidade e de seus sentidos. Tampouco parece correto falar em personificação nesse contexto, embora alguns dos elementos do espaço descrito sejam investidos de características e

fragmentum, nº 8. Laboratório Corpus: UFSM, 2004. 
atitudes humanas. Mais adequado seria afirmar que esses elementos - chuva, água, gotas, árvores - ganham vida e passam à categoria de seres animados. Esse tipo de representação do espaço entra em conflito e é, até mesmo, incompatível com uma lógica racionalista e uma concepção objetivista do mundo. Ele expressaria e, ao mesmo tempo, seria resultado de uma visão mítica do mundo.

Com uma escrita que Carmen Lúcia Tindó Secco chama de "mitopoética" ${ }^{18}$, devido à sua carga de lirismo, à sua inventividade verbal e à utilização de mitos, ritos e sonhos como caminhos ficcionais, o autor dá vida aos objetos e aos elementos constituintes do espaço. Assim acontece com a bota no conto $O$ Apocalipse privado do tio Geguê ("Ela veio cair junto de mim, pesada e grave" p. 42); com o embondeiro em $O$ embondeiro que sonhava pássaros ("Aquela árvore é capaz de grandes tristezas" - p. 65); e com o barco em $O$ pescador cego ("A maré estava baixa e a embarcação deitara-se de barriga na areia, espreguicenta" - p. 101). Calçado, árvore, embarcação: cada um deles é investido de qualidades, capacidades e comportamentos humanos, ou antes mais próprios a seres animados.

No entanto, deve-se notar que, se existe algo como uma personificação ou animação de coisas inertes, também existe nas narrativas um processo que leva à identificação do homem com os objetos ou com o espaço. Em O Apocalipse privado do tio Geguê, a identificação se dá pela falta. O narrador, menino que não conhecera mãe nem pai e havia sido criado pelo tio, estabelece semelhanças entre ele e a bota, reencontrada após ter sido enterrada: "Lhe apliquei cuidados como se fosse uma criança. Um menino órfão, tal qual eu" (p. 42). Na história de $\mathrm{O}$ embondeiro que sonhava pássaros, a identificação acontece através do sonho do menino. Estando dentro do embondeiro, à espera do vendedor, Tiago adormece e, enquanto os colonos colocam fogo na árvore, começa a sonhar: "seus cabelos se figuravam pequenitas folhas, pernas e braços se madeiravam" (p. 70). No conto O pescador cego o uso da paralepse (excesso de informação) permite que, através do ponto de vista de Salima, o pescador Maneca Mazembe seja comparado com o barco, o qual está parado desde sua mutilação: "Olhou o marido regressando e viu como se parentavam, homem e coisa: este, carente da luz; aquele, saudoso das ondas" (p. 101). Desse modo, a palavra transforma a realidade; a imagem poética muda a essência dos seres e das coisas.

fragmentum, no 8. Laboratório Corpus: UFSM, 2004. 
Procurou-se mostrar nesse texto que é possível estudar o romance e os contos de Mia Couto a partir de uma perspectiva mítica, a qual se conforma na relação do mito com a história no interior das narrativas. Notou-se que, se de uma parte essas narrativas figuram de maneira realista fatos e momentos históricos importantes do país, de outra parte apresentam um forte conteúdo mítico, cuja expressão pode ser a narração do acontecimento insólito (a transfiguração do real) ou a criação de imagens metamorfoseadoras, através da linguagem. Além disso, como se pôde depreender dessa consideração preliminar, a obra de Mia Couto, embora não possa ser simplesmente fixada como realismo maravilhoso, apresenta vários pontos em comum com a modalidade de literatura representada nessa categoria.

\section{NOTAS}

* Aluno do Programa de Pós-Graduação em Letras - Nível Mestrado - da Universidade Federal de Santa Maria. Membro do Laboratório Corpus. Bolsista da CAPES.

${ }^{1}$ COUTO, Mia. Cada homem é uma raça. Rio de Janeiro: Nova Fronteira, 1998.

${ }^{2}$ MIELIETINSKI, E. M. A poética do mito. Rio de Janeiro: ForenseUniversitária, 1987. p. 350.

${ }^{3}$ Idem, ibidem, p. 433.

${ }^{4}$ Idem, ibidem, p. 383.

${ }^{5}$ ELIADE, Mircea. Mito e realidade. 6. ed. São Paulo: Perspectiva, 2002. p. 7.

${ }^{6}$ SAID, Edward W. Cultura e imperialismo. São Paulo: Companhia das Letras, 1995. p. 88.

${ }^{7}$ Idem, ibidem, p. 55.

8 AHMAD, Aijaz. Linhagens do presente. São Paulo: Boitempo, 2002. p. 26.

9 Idem, ibidem, p. 42-43.

10 BHABHA, Homi K. O local da cultura. Belo Horizonte: UFMG, 1998. p. 105-128.

${ }^{11}$ CHIAMPI, Irlemar. O realismo maravilhoso: forma e ideologia no romance hispano-americano. São Paulo: Perspectiva, 1980. p. 61.

12 TODOROV, Tzvetan. Introdução à literatura fantástica. São Paulo: Perspectiva, 1975. p. 31. 
CARPENTIER, Alejo. Tientos y diferencias. "De lo real maravilhoso americano". Buenos Aires: Calicanto, 1976. p. 83-99.

14 É preciso, entretanto, levar em conta o perigo de uma generalização como essa. Depara-se com o problema da unidade das nações africanas em torno de uma mitologia comum. Appiah argumenta que "as semelhanças econômicas e da história colonial da África não justificam a suposição de uma unidade metafísica ou mítica, exceto se seguirmos os pressupostos mais horripilantemente deterministas". APPIAH, Kwame A. Na casa de meu pai: a África na filosofia da cultura. Rio de Janeiro: Contraponto, 1997. p. 122.

${ }^{15}$ GENETTE, Gérard. Discurso da narrativa. Lisboa: Vega, s.d. p. 195.

${ }_{16}^{16}$ CHIAMPI, Irlemar, 1980. p. 61.

17 Idem, ibidem, p. 79.

18 SECCO, Carmen Lúcia Tindó Ribeiro. "O ar, as águas e os sonhos no universo poético da ficção de Mia Couto". Cragoatá, Niterói, n. 5, 2. sem. 1998. p. 159-169.

\section{REFERÊNCIAS BIBLIOGRÁFICAS}

AHMAD, Aijaz. Linhagens do presente. São Paulo: Boitempo, 2002.

APPIAH, Kwame. Na casa de meu pai: a África na filosofia da cultura. Rio de Janeiro: Contraponto, 1997.

BHABHA, Homi K. O local da cultura. Belo Horizonte: UFMG, 1998. CARPENTIER, Alejo. Tientos y diferencias. "De lo real maravilhoso americano". Buenos Aires: Calicanto, 1976.

CHIAMPI, Irlemar. O realismo maravilhoso: forma e ideologia no romance hispano-americano. São Paulo: Perspectiva, 1980.

COUTO, Mia. Cada homem é uma raça. Rio de Janeiro: Nova Fronteira, 1998.

ELIADE, Mircea. Mito e realidade. 6. ed. São Paulo: Perspectiva, 2002.

GENETTE, Gérard. Discurso da narrativa. Lisboa: Vega, s.d.

MIELIETINSKI, E. M. A poética do mito. Rio de Janeiro: ForenseUniversitária, 1987.

SAID, Edward W. Cultura e imperialismo. São Paulo: Companhia das Letras, 1995. 
SECCO, Carmen Lúcia Tindó Ribeiro. "O ar, as águas e os sonhos no universo poético da ficção de Mia Couto". Cragoatá, Niterói, n. 5, 2. sem. 1998.

TODOROV, Tzvetan. Introdução à literatura fantástica. São Paulo: Perspectiva, 1975. 